\title{
Ankylosing Spondylitis Is Associated with Increased Prevalence of Left Ventricular Hypertrophy
}

\author{
Helga Midtbø, Eva Gerdts, Inger Jorid Berg, Silvia Rollefstad, Roland Jonsson, \\ and Anne Grete Semb
}

ABSTRACT. Objective. Ankylosing spondylitis (AS) is associated with increased risk for cardiovascular disease (CVD). Left ventricular (LV) hypertrophy is a strong precursor for clinical CVD. The aim of our study was to assess whether having AS was associated with increased prevalence of LV hypertrophy.

Methods. Clinical and echocardiographic data from 139 AS patients and 126 age- and sex-matched controls was used. LV mass was calculated according to guidelines and indexed to height ${ }^{2.7}$. LV hypertrophy was considered present if LV mass index was $>49.2 \mathrm{~g} / \mathrm{m}^{2.7}$ in men and $>46.7 \mathrm{~g} / \mathrm{m}^{2.7}$ in women. Results. Patients with AS were on average $49 \pm 12$ years old, and $60 \%$ were men. The prevalence of hypertension (HTN; $35 \%$ vs $41 \%$ ) and diabetes (5\% vs $2 \%$ ) was similar among patients and controls, while patients with AS had higher serum C-reactive protein level (CRP; $p<0.001)$. The prevalence of LV hypertrophy was higher in patients with AS compared to controls $(15 \%$ vs $6 \%, \mathrm{p}=0.01)$. In multivariable logistic regression analysis, having AS was associated with OR 6.3 (95\% CI 2.1-19.3, $\mathrm{p}=0.001$ ) of having LV hypertrophy independent of the presence of HTN, diabetes, and obesity. In multivariable linear regression analyses, having AS was also associated with higher LV mass ( $\beta 0.15$, $\mathrm{p}=0.007$ ) after adjusting for CVD risk factors including sex, body mass index, systolic blood pressure, diabetes, and serum CRP (multiple $\mathrm{R}^{2}=0.41, \mathrm{p}<0.001$ ).

Conclusion. Having AS was associated with increased prevalence of LV hypertrophy independent of CVD risk factors. This finding strengthens the indication for thorough CVD risk assessment in patients with AS. (First Release June 1 2018; J Rheumatol 2018;45:1249-55; doi:10.3899/jrheum.171124)

Key Indexing Terms:

ANKYLOSING SPONDYLITIS

LEFT VENTRICULAR HYPERTROPHY

\section{ECHOCARDIOGRAPHY} HYPERTENSION
Ankylosing spondylitis (AS) is an inflammatory disease of the axial skeleton and has a strong association with HLA-B27 ${ }^{1}$. Cardiac involvement in AS has been acknowledged for a long time, and previous studies using echocardiography have shown increased prevalence of aortic root

From the Department of Heart Disease and Department of Rheumatology, Haukeland University Hospital; Broegelmann Research Laboratory, Department of Clinical Science, University of Bergen, Bergen; Department of Rheumatology, Diakonhjemmet Hospital; Preventive Cardio-Rheuma Clinic, Department of Rheumatology, Diakonhjemmet Hospital, Oslo, Norway.

This study has received funding from the South-Eastern and Western Regional Health Authorities of Norway.

H. Midtb $\phi$, Postdoctor, MD, PhD, Department of Heart Disease, Haukeland University Hospital; E. Gerdts, Professor, MD, PhD,

Department of Clinical Science, University of Bergen; I.J. Berg, Consultant Rheumatologist, MD, PhD, Department of Rheumatology, Diakonhjemmet Hospital; S. Rollefstad, Postdoctor, MD, PhD, Preventive Cardio-Rheuma Clinic, Department of Rheumatology, Diakonhjemmet Hospital; R. Jonsson, Professor, DMD, PhD, Broegelmann Research Laboratory, Department of Clinical Science, University of Bergen, and Department of Rheumatology, Haukeland University Hospital; A.G. Semb, Consultant Cardiologist,

Senior Researcher, MD, PhD, Preventive Cardio-Rheuma Clinic,

Department of Rheumatology, Diakonhjemmet Hospital.

Address correspondence to Dr. H. Midtb $\phi$, Department of Heart Disease, Haukeland University Hospital, Jonas Lies vei 65, 5021 Bergen, Norway.

E-mail: helgamit@online.no

Accepted for publication February 14, 2018. dilatation and valvular disease ${ }^{2}$, as well as reduced left ventricular (LV) function ${ }^{3}$ and subclinical atherosclerosis ${ }^{4}$.

Chronic inflammatory diseases such as AS are now recognized as risk factors for cardiovascular disease $(\mathrm{CVD})^{5,6,7}$. It is well documented that clinical CVD is preceded by subclinical changes in the heart and arteries, and that presence of such subclinical organ damage is strongly associated with impaired prognosis $8,9,10,11,12$. This is particularly true for LV hypertrophy. In hypertensive patients, presence of LV hypertrophy was associated with a $54 \%$ increase in risk of $\mathrm{CV}$ events including acute coronary syndromes, and stroke ${ }^{8}$. In the Framingham Heart Study, LV hypertrophy was associated with a 2-fold increased risk of sudden death after adjustment for possible confounders ${ }^{12}$. However, although patients with AS have increased risk for CVD, it has not been documented whether having AS is associated with increased prevalence of LV hypertrophy. The aim of our present study was to determine whether AS was associated with presence of LV hypertrophy independent of known confounders.

\section{MATERIALS AND METHODS}

Study population. Patients with AS, diagnosed by the modified New York criteria $^{13}$, were recruited from a previously established cohort of patients with AS at the Department of Rheumatology, Diakonhjemmet Hospital. Details of this cohort have been published previously ${ }^{14,15}$. In short, this was

Personal non-commercial use only. The Journal of Rheumatology Copyright $\odot$ 2018. All rights reserved. 
a cross-sectional study, where patients were recruited from the Oslo area in Norway and the gross majority of the patients included were white. The study started in 2008 and data collection was completed in 2010, including control subjects. Of 257 patients invited to participate, 159 agreed (response rate $62 \%$ ). Of those, 17 patients were excluded because of established CVD (defined as previous cardiac surgery/intervention, myocardial infarction, angina pectoris, transitory ischemic attack, cerebral infarction, and intermittent claudication). Additional 3 patients were excluded because of insufficient quality of the echocardiographic images. Thus, for our present analyses, a total of 139 patients with AS were included.

Control subjects. Control subjects without inflammatory joint disease, stratified for age, sex, and residential area to the participating patients with AS, were randomly selected by Statistics Norway. Of the 329 invited control subjects, 132 (40\%) agreed to participate. Six control subjects were excluded because of established CVD, leaving a control group of 126 subjects. All patients and controls signed an informed consent according to the Declaration of Helsinki, and the study protocol was approved by the South Eastern Norwegian Regional Committee for Medical and Health Research Ethics (approval no. S-02059).

AS disease characteristics. Duration of disease was defined from the onset of symptoms as previously recommended ${ }^{16}$. HLA-B27 status was obtained from medical records (available in 116 patients with AS). Disease activity was calculated by the Bath Ankylosing Disease Activity Index (BASDAI) ${ }^{17}$ and the Ankylosing Spondylitis Disease Activity Score (ASDAS)-C-reactive protein $(\mathrm{CRP})^{18}$. Physical function was assessed by the Bath Ankylosing Spondylitis Functional Index (BASFI) ${ }^{19}$

Health status. Self-reported information about the participants' medical history, smoking status, and current medical therapy were collected by a standardized questionnaire. The information was later quality-assured by the consultant cardiologist (AGS) during the consultation. Obesity was defined as body mass index $(\mathrm{BMI}) \geq 30 \mathrm{~kg} / \mathrm{m}^{2}$.

Laboratory measurements. Total cholesterol and CRP were analyzed in fasting blood samples by the COBAS 6000 machine (Roche Diagnostics). Erythrocyte sedimentation rate (ESR) was analyzed by the Westergren method.

Blood pressure. Brachial blood pressure was measured in accordance with the European Society of Hypertension guidelines using an OMRON M7 apparatus ${ }^{20}$. The average of the 2 last measurements was taken as the clinic blood pressure in the individual subject. Hypertension (HTN) was defined as use of antihypertensive medication, a history of HTN, or elevated blood pressure (systolic office blood pressure $\geq 140 \mathrm{mmHg}$ and/or diastolic office blood pressure $\geq 90 \mathrm{mmHg}$ ) at the clinical visit.

Echocardiography. The transthoracic echocardiograms were recorded during the period between 2008 and 2010 using a Vivid 7 (General Electric Vingmed Ultrasound) scanner and a standardized protocol. All the echocardiographic images were stored electronically and forwarded for analysis at the Echocardiography Core Laboratory at Haukeland University Hospital, Bergen, Norway. The echocardiograms were analyzed by the same reader (HM) on digital workstations equipped with Image Arena software version 4.1 (TomTec Imaging Systems $\mathrm{GmbH}$ ), and proofread for quality assurance by the same highly experienced reader (EG). Quantitative echocardiography in the study was performed following the joint guidelines from the European Association of Cardiovascular Imaging and American Society of Echocardiography $^{21}$. LV mass was indexed for height ${ }^{2.7}$, and LV hypertrophy was considered present if LV mass index was $>49.2 \mathrm{~g} / \mathrm{m}^{2.7}$ in men and $>46.7$ $\mathrm{g} / \mathrm{m}^{2.7}$ in women ${ }^{8,9}$. Relative wall thickness was defined as twice LV posterior wall thickness/internal LV diameter ratio in end-diastole and considered high if it was $\geq 0.43^{22}$. LV geometry was defined from LV mass index and relative wall thickness in combination, and considered normal if both measures were normal; as concentric remodeling if high relative wall thickness but normal LV mass index was present; as eccentric LV hypertrophy if high LV mass index but normal relative wall thickness was present; and as concentric LV hypertrophy if both LV mass index and relative wall thickness were high ${ }^{21,22}$. LV systolic function was assessed from ejection fraction calculated by the biplane method of disks ${ }^{21}$. LV diastolic function was assessed from LV filling as the ratio of the peak mitral early (E) and late (A) velocities measured at the tips of mitral leaflets (E/A ratio), and LV filling pressure by the ratio of $\mathrm{E}$ and the early septal mitral annulus velocity $\left(\mathrm{e}^{\prime}\right)^{23}$. Aortic valve regurgitation was graded by color Doppler ${ }^{24}$.

Statistics. The statistical analyses were done using IBM SPSS statistics version 23.0 (IBM). Categorical variables are presented as n (\%). Normally distributed continuous data are expressed as mean and SD, and non-normally distributed continuous data (ESR and CRP) as median and interquartile range. Non-normally distributed variables were log-transformed before inclusion in univariable and multivariable analyses. Comparisons between groups were performed by the chi-squared test and the 2-sample Student t test as appropriate. Univariable associations were assessed with linear regression models, and standardized $\beta$ coefficients and $\mathrm{p}$ values were reported. Multivariable linear regression analyses were run with an enter method and co-linearity tools Results were reported as multiple $\mathrm{R}^{2}$ for the overall models, and standardized $\beta$ coefficients for the individual variables. Results of logistic regression are reported as OR and 95\% CI for the individual variables. A 2-tailed p value of $<0.05$ was considered statistically significant in all analyses.

\section{RESULTS}

Clinical characteristics. The patients with AS were less obese than controls $(p=0.03)$, while the prevalence of HTN, diabetes, and current smoking did not differ (Table 1). Further, patients with AS had higher CRP and ESR levels, and used more prednisolone and nonsteroidal antiinflammatory drugs (NSAID) than did the controls ( $p<0.05$, Table 1$)$. The mean disease activity in patients with AS was moderate to high according to BASDAI and ASDAS, but the functional capacity judged by the BASFI score was on average good.

LV hypertrophy, mass, and geometry. Patients with AS had higher prevalence of LV hypertrophy than controls ( $15 \%$ vs $6 \%, \mathrm{p}=0.01$; Table 2). In particular, patients with AS had higher prevalence of eccentric LV hypertrophy, while control subjects had higher prevalence of concentric remodeling (Figure 1). Of note, the prevalence of aortic and mitral regurgitation did not differ between the groups, and none had more than mild to moderate insufficiencies (Table 2). Further, patients with AS had lower LV ejection fraction compared to controls $(\mathrm{p}=0.006)$, but the diastolic function assessed by LV filling and $\mathrm{e}^{\prime}$ was similar (Table 2). In multivariable logistic regression analysis, having AS was associated with a 6.3-fold higher OR (95\% CI 2.1-19.3, p = 0.001) of having LV hypertrophy after adjusting for sex, HTN, diabetes, and obesity (Table 3). When evaluating patients with AS separately, AS disease characteristics such as disease duration and antirheumatic medication were not associated with LV hypertrophy (Table 3). The presence of HTN, obesity, diabetes, and male sex emerged as the main covariables of LV hypertrophy in patients with AS.

In subsequent analyses focusing on LV mass, having AS ( $\beta 0.15, p=0.007)$ was associated with higher LV mass after adjusting for BMI, sex, systolic blood pressure, age, diabetes, and serum CRP levels (Table 4). There was a univariable association between higher CRP levels and LV mass in the total study population (Table 4), that became nonsignificant after adjusting for other CV risk factors (Table 4). There were no significant associations between AS disease characteristics 
Table 1. Clinical characteristics of the study population. Values are mean $\pm \mathrm{SD}$ or $\mathrm{n}(\%)$ unless otherwise specified.

\begin{tabular}{|c|c|c|c|}
\hline Characteristics & AS, $n=139$ & Controls, $\mathrm{n}=126$ & $\mathrm{p}$ \\
\hline Age, yrs & $49.1 \pm 11.7$ & $52.1 \pm 11.4$ & 0.04 \\
\hline Men & $84(60)$ & $73(58)$ & 0.68 \\
\hline $\mathrm{BMI}, \mathrm{kg} / \mathrm{m}^{2}$ & $25.2 \pm 3.5$ & $25.7 \pm 3.9$ & 0.30 \\
\hline Obesity & $11(8)$ & $21(17)$ & 0.03 \\
\hline Current smoking & $26(19)$ & $28(22)$ & 0.48 \\
\hline Diabetes & $7(5)$ & $3(2)$ & 0.26 \\
\hline Total serum cholesterol, mg/dl & $209 \pm 43$ & $224 \pm 35$ & 0.009 \\
\hline Use of statins & $9(7)$ & $13(10)$ & 0.26 \\
\hline ESR, mm/h, median (IQR) & $16(7-29)$ & $8(4-14)$ & $<0.001$ \\
\hline CRP, mg/l, median (IQR) & $3(1-10)$ & $1(1-2)$ & $<0.001$ \\
\hline \multicolumn{4}{|l|}{ Blood pressure and hypertension } \\
\hline Systolic blood pressure, $\mathrm{mmHg}$ & $126 \pm 17$ & $130 \pm 21$ & 0.08 \\
\hline Diastolic blood pressure, $\mathrm{mmHg}$ & $78 \pm 10$ & $78 \pm 11$ & 0.94 \\
\hline Hypertension & $49(35)$ & $52(41)$ & 0.31 \\
\hline Medically treated hypertensive patients* & $26(53)$ & $23(44)$ & 0.38 \\
\hline Use of ACE or ARB* & $16(33)$ & $13(25)$ & 0.40 \\
\hline Use of beta blockers* & $6(12)$ & $8(15)$ & 0.65 \\
\hline Use of calcium channel blockers* & $5(10)$ & $7(14)$ & 0.61 \\
\hline Use of diuretics* & $10(20)$ & $7(14)$ & 0.35 \\
\hline \multicolumn{4}{|l|}{ AS disease characteristics } \\
\hline Disease duration, yrs & $23.3 \pm 11$ & N/A & \\
\hline ASDAS score & $2.2 \pm 1.0$ & N/A & \\
\hline BASDAI score & $3.5 \pm 1.8$ & N/A & \\
\hline BASFI score & $2.4 \pm 2.0$ & N/A & \\
\hline HLA-B27-positive $(\mathrm{n}=116)$ & $109(94)$ & N/A & \\
\hline \multicolumn{4}{|l|}{ Current use of antirheumatic medication } \\
\hline TNFi & $26(19)$ & N/A & \\
\hline Synthetic DMARD & $21(15)$ & N/A & \\
\hline NSAID & $92(66)$ & $17(14)$ & $<0.001$ \\
\hline Prednisolone & $11(8)$ & $3(2)$ & 0.04 \\
\hline
\end{tabular}

*Percentages are calculated among hypertensive subjects. ACE: angiotensin-converting enzyme inhibitors; ARB: angiotensin II receptor blockers; AS: ankylosing spondylitis; ASDAS: Ankylosing Spondylitis Disease Activity Score; BASDAI: Bath Ankylosing Disease Activity Index; BASFI: Bath Ankylosing Spondylitis Functional Index; BMI: body mass index; CRP: C-reactive protein; DMARD: disease-modifying antirheumatic drugs; ESR: erythrocyte sedimentation rate; IQR: interquartile range; N/A: not applicable; NSAID: nonsteroidal antiinflammatory drugs; TNFi: tumor necrosis factor inhibitors.

and LV mass in univariable analyses among patients with AS, except for a weak association of higher LV mass with use of $\operatorname{NSAID}(\beta 0.18, \mathrm{p}=0.04)$. However, this association became nonsignificant after adjusting for $\mathrm{CV}$ risk factors in another multivariable model (data not shown).

Although having AS was not associated with increased LV relative wall thickness, the duration of having AS was associated with higher LV relative wall thickness $(\beta 0.24$, $\mathrm{p}=0.005)$ in univariable analysis. But after adjusting for age in a multivariable model, this association became statistically nonsignificant (data not shown).

\section{DISCUSSION}

To our knowledge, our present study is the first to demonstrate that patients with AS have an increased prevalence of LV hypertrophy, reflecting subclinical CVD. Of note, having AS was associated with the presence of LV hypertrophy and higher LV mass independent of CV risk factors. Further, AS disease activity and use of antirheumatic medication was not associated with LV hypertrophy, indicating that having AS is associated with LV hypertrophy per se.

Altered LV structure has previously been reported in other chronic inflammatory disorders, such as rheumatoid arthritis (RA) ${ }^{25,26}$ and gout ${ }^{27}$ (in particular when CV risk factors such as HTN, obesity, and diabetes are present ${ }^{28,29}$ ); this was also the case for patients with AS in our study. In previous studies in patients with AS, the prevalence of HTN was reported to be higher, and the prevalence of diabetes was comparable to that of the general population ${ }^{30,31}$. In contrast, in our current study, the prevalence of HTN was similar between patients with AS and controls, while the controls had more obesity. The high prevalence of concentric remodeling seen among control subjects in our study is likely to be a result of the high prevalence of obesity 22,29 . In obesity, the visceral and pericardial fat tissue produces angiotensinogen, adipokinins, proinflammatory cytokines, and mineralocorticoid-releasing factors, leading to chronic CV inflammation and subsequent myocardial fibrosis and increased LV wall thickness ${ }^{32}$. On

Personal non-commercial use only. The Journal of Rheumatology Copyright (c) 2018. All rights reserved. 
Table 2. Echocardiographic characteristics in patients with AS and controls. Values are mean \pm SD or n (\%).

\begin{tabular}{lccc}
\hline Characteristics & AS, $\mathrm{n}=139$ & Controls, $\mathrm{n}=126$ & $\mathrm{p}$ \\
\hline LV structure & & & \\
$\quad$ LV septum thickness at end-diastole, $\mathrm{cm}$ & $0.98 \pm 0.22$ & $0.95 \pm 0.18$ & 0.26 \\
LV posterior wall thickness at end-diastole, cm & $0.86 \pm 0.16$ & $0.85 \pm 0.16$ & 0.35 \\
LV diameter at end-diastole, cm & $4.9 \pm 0.6$ & $4.8 \pm 0.5$ & 0.06 \\
LV mass, g & $164 \pm 49$ & $152 \pm 49$ & 0.05 \\
LV mass index, g/m ${ }^{2.7}$ & $36.6 \pm 9.8$ & $34.3 \pm 10.0$ & 0.06 \\
Relative wall thickness, ratio & $0.35 \pm 0.08$ & $0.35 \pm 0.08$ & 0.95 \\
Concentric LV geometry & $18(13)$ & $27(21)$ & 0.07 \\
LV hypertrophy & $21(15)$ & $7(6)$ & 0.01 \\
LV function & $1.3 \pm 0.4$ & $1.4 \pm 0.5$ & 0.75 \\
E/A ratio & $8.4 \pm 3.1$ & $8.4 \pm 2.8$ & 0.89 \\
E/e' & $66 \pm 6$ & $68 \pm 5$ & 0.006 \\
$\quad$ Ejection fraction, \% & & & \\
Valvular function & $19(14)$ & $21(17)$ & 0.50 \\
Aortic regurgitation, any & $5(4)$ & $5(4)$ & 0.87 \\
Moderate aortic regurgitation & $63(45)$ & $61(48)$ & 0.62 \\
$\quad$ Mitral regurgitation, any & & & \\
\hline
\end{tabular}

AS: ankylosing spondylitis; LV: left ventricular; E/A: early/atrial transmitral peak velocities; E/e': early peak blood velocity/early diastolic tissue velocity at septal border of mitral annulus.

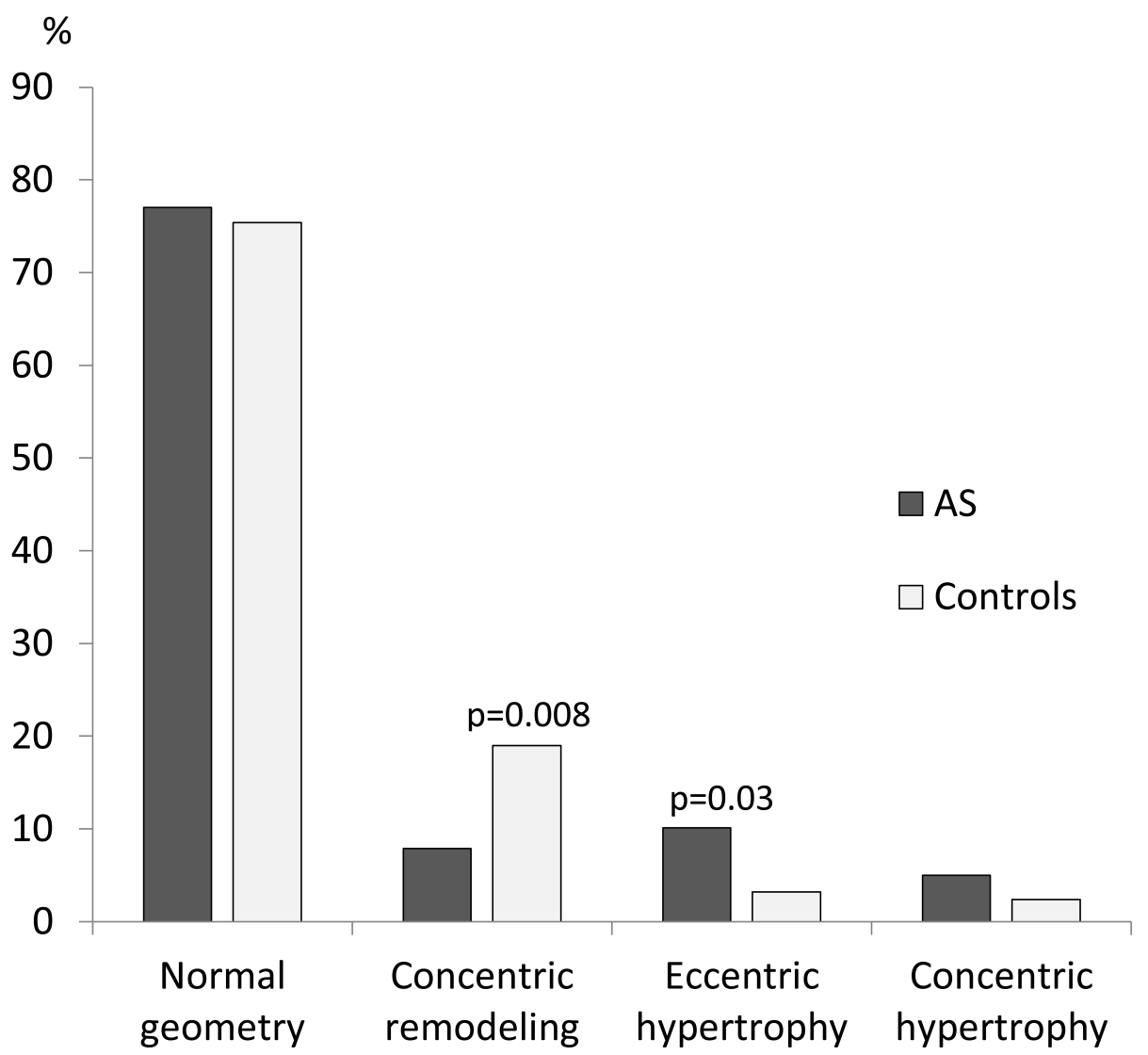

Figure 1. LV geometry in patients with AS and controls. AS: ankylosing spondylitis; LV: left ventricular. 
Table 3. Univariable and multivariable associations of LV hypertrophy.

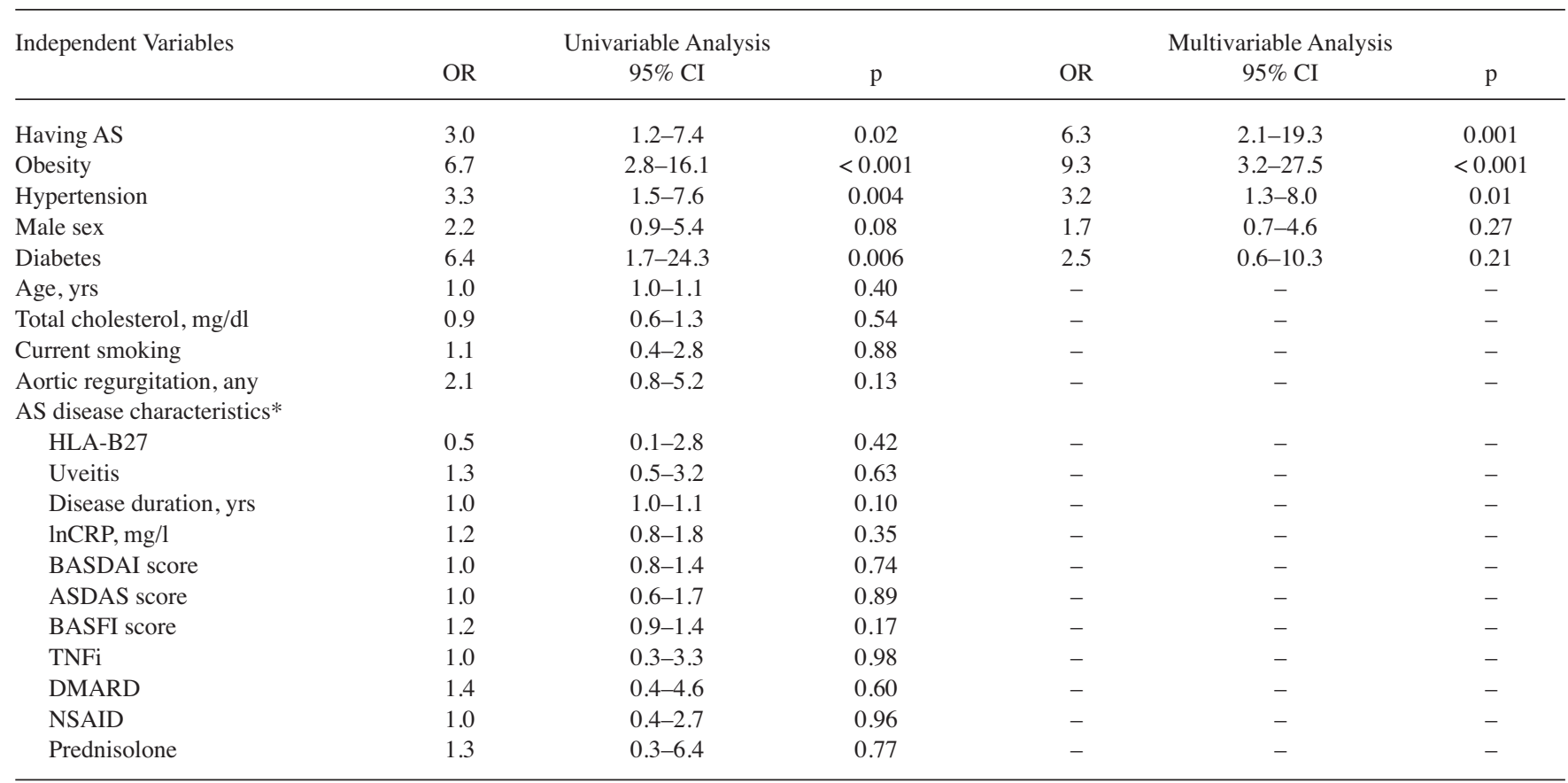

* Tested among patients with AS. AS: ankylosing spondylitis; ASDAS: Ankylosing Spondylitis Disease Activity Score; BASDAI: Bath Ankylosing Disease Activity Index; BASFI: Bath Ankylosing Spondylitis Functional Index; DMARD: disease-modifying antirheumatic drugs; lnCRP: natural logarithm of C-reactive protein; LV: left ventricular; NSAID: nonsteroidal antiinflammatory drugs; TNFi: tumor necrosis factor inhibitors.

Table 4. Univariable and multivariable associations of LV mass in patients with AS and controls.

\begin{tabular}{lcccc}
\hline Variables & \multicolumn{2}{c}{ Univariable } & \multicolumn{2}{c}{ Multivariable* } \\
& $\beta$ & $\mathrm{p}$ & $\beta$ & $\mathrm{p}$ \\
\hline Having AS & 0.12 & 0.05 & 0.15 & 0.007 \\
Male sex & 0.53 & $<0.001$ & 0.41 & $<0.001$ \\
BMI, kg/m & 0.39 & $<0.001$ & 0.25 & $<0.001$ \\
$\begin{array}{l}\text { Systolic blood pressure, } \\
\quad \text { mmHg }\end{array}$ & 0.37 & $<0.001$ & 0.22 & $<0.001$ \\
Diabetes & 0.14 & 0.02 & 0.05 & 0.33 \\
lnCRP, mg/l & 0.14 & 0.03 & -0.04 & 0.53 \\
Age, yrs & 0.02 & 0.80 & -0.04 & 0.46 \\
\hline
\end{tabular}

* Multiple $\mathrm{R}^{2} 0.41, \mathrm{p}<0.001$. AS: ankylosing spondylitis; BMI: body mass index, lnCRP: natural logarithm of C-reactive protein; LV: left ventricular.

the other hand, having AS is associated with increased risk for aortic valve regurgitation ${ }^{2,33}$. Presence of aortic regurgitation has been associated with larger LV cavity dimensions and eccentric LV hypertrophy ${ }^{34}$, and could represent a pathophysiological mechanism of LV hypertrophy in patients with AS when the aortic valve regurgitation is at least of moderate severity ${ }^{24}$. In our present study population, the vast majority of aortic valve regurgitation was of mild severity (grade 1), and presence of aortic valve regurgitation was therefore not identified as a covariable of LV hypertrophy.

In line with previous studies in patients with $\mathrm{AS}^{2,33}$, the prevalence of aortic regurgitation was $14 \%$ in our present study. However, the prevalence of aortic regurgitation in the control subjects was $17 \%$, which was higher than in the earlier studies. In the Framingham Offspring Study, the prevalence of aortic regurgitation was $13.0 \%$ in men and $8.5 \%$ in women, with increasing prevalence with age in both sexes ${ }^{35}$. The higher prevalence of aortic regurgitation among our controls could not only represent statistical variance in a relatively small study sample, but also characteristics such as a high prevalence of male sex and CV risk factors in our control group.

The traditional understanding that LV hypertrophy is mainly related to hemodynamic factors such as blood pressure has recently been challenged. Although reduction of LV mass during systematic antihypertensive treatment has been demonstrated in randomized clinical trials ${ }^{22,36}$, previous publications from real-world practice have shown that persistent LV hypertrophy is common despite modern antihypertensive treatment ${ }^{37,38}$. These results suggest that nonhemodynamic factors such as inflammation are important in the pathogenesis of LV hypertrophy ${ }^{39}$. The present results are in line with these findings. In AS, we have previously demonstrated that higher disease activity by ASDAS was associated with increased arterial stiffness ${ }^{15}$, and that a history of uveitis was associated with presence of HTN and atherosclerosis ${ }^{14}$. Also in RA, disease activity has been associated with higher risk of subclinical and clinical $\mathrm{CVD}^{40,41}$. However, accelerated atherosclerosis was not found in AS patients with low disease activity in a previous metaanalysis ${ }^{42}$. Recently, in a small study of 14 patients with AS using cardiac magnetic resonance

Personal non-commercial use only. The Journal of Rheumatology Copyright (c) 2018. All rights reserved. 
imaging (MRI), it was found that increased myocardial extracellular volume, a marker of diffuse interstitial fibrosis, was associated with higher inflammatory markers (CRP and ESR $)^{43}$. Presence of excessive myocardial fibrosis contributes to $\mathrm{LV}$ hypertrophy ${ }^{39}$, providing a possible underlying mechanism for our finding of increased prevalence of LV hypertrophy in AS. However, in our present study, neither AS disease activity nor uveitis was associated with presence of LV hypertrophy. AS disease duration was also not associated with LV hypertrophy, possibly reflecting that development of LV hypertrophy with increasing age is closely dependent on presence of concomitant $\mathrm{CV}$ risk factors ${ }^{44}$.

A valid question would be whether LV mass could be reduced by immunomodulation therapy in patients with AS. To the best of our knowledge, this has not been tested in patients with AS. However, a small echocardiographic study of 28 patients with RA demonstrated a significant reduction of LV mass index after 6 months of treatment with a tumor necrosis factor $\alpha$ (TNF- $\alpha$ ) inhibitor ${ }^{45}$. In another small cardiac MRI study in 20 patients with RA, LV mass index was significantly reduced with use of the interleukin 6 inhibitor tocilizumab ${ }^{46}$. In line with these findings, induction of $\mathrm{LV}$ hypertrophy by angiotensin II has also been shown to be attenuated in TNF- $\alpha$ knockout mice compared to wild-type mice ${ }^{47}$. These results suggest an emerging role of inflammation in the development of LV hypertrophy in inflammatory diseases like AS. However, the effects of immunomodulation therapy and AS disease activity in relation to LV structure and hypertrophy need to be further investigated in a prospective study.

Some important study limitations should be mentioned. The cross-sectional study design is unsuited to demonstrate any causality between having AS and presence of LV hypertrophy. The low participation rate among invited controls may also have introduced a selection bias. The study strengths are the use of a core laboratory for analysis of echocardiography as recommended for echocardiographic studies $^{48}$, and prognostically validated cutoff values for identification of LV hypertrophy ${ }^{8,9}$.

Having AS was associated with higher prevalence of LV hypertrophy, reflecting subclinical CVD, independent of CV risk factors. The results could help to explain the increased risk of CVD in patients with $\mathrm{AS}$ and strengthens the indication for thorough $\mathrm{CV}$ risk assessment in patient groups with inflammatory disorders. Of concern is the fact that only 53\% of hypertensive AS patients were using antihypertensive treatment in our study, pointing to the unmet potential of reducing prevalent and incident LV hypertrophy in AS by following guideline recommendations for $\mathrm{CV}$ disease prevention ${ }^{20}$. Echocardiography should be included in routine $\mathrm{CV}$ risk assessment in patients with AS, given that unmanaged LV hypertrophy is associated with poor prognosis 8,22 .

\section{REFERENCES}

1. Dean LE, Jones GT, MacDonald AG, Downham C, Sturrock RD, Macfarlane GJ. Global prevalence of ankylosing spondylitis.
Rheumatology 2014;53:650-7.

2. Roldan CA, Chavez J, Wiest PW, Qualls CR, Crawford MH. Aortic root disease and valve disease associated with ankylosing spondylitis. J Am Coll Cardiol 1998;32:1397-404.

3. Chen Y, Chung HY, Zhao CT, Wong A, Zhen Z, Tsang HH, et al. Left ventricular myocardial dysfunction and premature atherosclerosis in patients with axial spondyloarthritis. Rheumatology 2015;54:292-301.

4. Rueda-Gotor J, Llorca J, Corrales A, Blanco R, Fuentevilla P, Portilla V, et al. Carotid ultrasound in the cardiovascular risk stratification of patients with ankylosing spondylitis: results of a population-based study. Clin Exp Rheumatol 2016;34:885-92.

5. Piepoli MF, Hoes AW, Agewall S, Albus C, Brotons C, Catapano AL, et al; ESC Scientific Document Group. 2016 European Guidelines on cardiovascular disease prevention in clinical practice: The Sixth Joint Task Force of the European Society of Cardiology and Other Societies on Cardiovascular Disease Prevention in Clinical Practice (constituted by representatives of 10 societies and by invited experts) developed with the special contribution of the European Association for Cardiovascular Prevention \& Rehabilitation (EACPR). Eur Heart J 2016;37:2315-81.

6. Semb AG, Ikdahl E, Hisdal J, Olsen IC, Rollefstad S. Exploring cardiovascular disease risk evaluation in patients with inflammatory joint diseases. Int J Cardiol 2016;223:331-6.

7. Agca R, Heslinga SC, Rollefstad S, Heslinga M, McInnes IB, Peters MJ, et al. EULAR recommendations for cardiovascular disease risk management in patients with rheumatoid arthritis and other forms of inflammatory joint disorders: 2015/2016 update. Ann Rheum Dis 2017;76:17-28

8. de Simone G, Izzo R, Chinali M, De Marco M, Casalnuovo G, Rozza F, et al. Does information on systolic and diastolic function improve prediction of a cardiovascular event by left ventricular hypertrophy in arterial hypertension? Hypertension 2010;56:99-104.

9. Gerdts E, Rosseb $\varnothing$ AB, Pedersen TR, Cioffi G, Lønnebakken MT, Cramariuc D, et al. Relation of left ventricular mass to prognosis in initially asymptomatic mild to moderate aortic valve stenosis. Circ Cardiovasc Imaging 2015;8:e003644.

10. Koren MJ, Devereux RB, Casale PN, Savage DD, Laragh JH. Relation of left ventricular mass and geometry to morbidity and mortality in uncomplicated essential hypertension. Ann Intern Med 1991;114:345-52.

11. Levy D, Garrison RJ, Savage DD, Kannel WB, Castelli WP. Prognostic implications of echocardiographically determined left ventricular mass in the Framingham Heart Study. N Engl J Med 1990;322:1561-6.

12. Haider AW, Larson MG, Benjamin EJ, Levy D. Increased left ventricular mass and hypertrophy are associated with increased risk for sudden death. J Am Coll Cardiol 1998;32:1454-9.

13. van der Linden S, Valkenburg HA, Cats A. Evaluation of diagnostic criteria for ankylosing spondylitis. A proposal for modification of the New York criteria. Arthritis Rheum 1984;27:361-8.

14. Berg IJ, Semb AG, van der Heijde D, Kvien TK, Hisdal J, Olsen IC, et al. Uveitis is associated with hypertension and atherosclerosis in patients with ankylosing spondylitis: a cross-sectional study. Semin Arthritis Rheum 2014;44:309-13.

15. Berg IJ, van der Heijde D, Dagfinrud H, Seljeflot I, Olsen IC, Kvien TK, et al. Disease activity in ankylosing spondylitis and associations to markers of vascular pathology and traditional cardiovascular disease risk factors: a cross-sectional study. J Rheumatol 2015;42:645-53.

16. Feldtkeller E, Erlendsson J. Definition of disease duration in ankylosing spondylitis. Rheumatol Int 2008;28:693-6.

17. Garrett S, Jenkinson T, Kennedy LG, Whitelock H, Gaisford P, Calin A. A new approach to defining disease status in ankylosing

Personal non-commercial use only. The Journal of Rheumatology Copyright $\subset$ $\subset$ 2018. All rights reserved 
spondylitis: the Bath Ankylosing Spondylitis Disease Activity Index. J Rheumatol 1994;21:2286-91 .

18. van der Heijde D, Lie E, Kvien TK, Sieper J, Van den Bosch F, Listing J, et al; Assessment of SpondyloArthritis international Society (ASAS). ASDAS, a highly discriminatory ASAS-endorsed disease activity score in patients with ankylosing spondylitis. Ann Rheum Dis 2009;68:1811-8.

19. Calin A, Garrett S, Whitelock H, Kennedy LG, O'Hea J, Mallorie P, et al. A new approach to defining functional ability in ankylosing spondylitis: the development of the Bath Ankylosing Spondylitis Functional Index. J Rheumatol 1994;21:2281-5.

20. Mancia G, Fagard R, Narkiewicz K, Redon J, Zanchetti A, Böhm M, et al. 2013 ESH/ESC guidelines for the management of arterial hypertension. Blood Press 2013;22:193-278.

21. Lang RM, Badano LP, Mor-Avi V, Afilalo J, Armstrong A, Ernande $\mathrm{L}$, et al. Recommendations for cardiac chamber quantification by echocardiography in adults: an update from the american society of echocardiography and the European association of cardiovascular imaging. J Am Soc Echocardiogr 2015;28:1-39.

22. Gerdts E, Cramariuc D, de Simone G, Wachtell K, Dahlöf B, Devereux RB. Impact of left ventricular geometry on prognosis in hypertensive patients with left ventricular hypertrophy (the LIFE study). Eur J Echocardiogr 2008;9:809-15.

23. Nagueh SF, Smiseth OA, Appleton CP, Byrd BF 3rd, Dokainish H, Edvardsen T, et al. Recommendations for the evaluation of left ventricular diastolic function by echocardiography: an update from the American Society of Echocardiography and the European Association of Cardiovascular Imaging. Eur Heart J Cardiovasc Imaging 2016;17:1321-60.

24. Lebowitz NE, Bella JN, Roman MJ, Liu JE, Fishman DP, Paranicas $\mathrm{M}$, et al. Prevalence and correlates of aortic regurgitation in American Indians: the Strong Heart Study. J Am Coll Cardiol 2000;36:461-7.

25. Myasoedova E, Davis JM 3rd, Crowson CS, Roger VL, Karon BL, Borgeson DD, et al. Brief report: rheumatoid arthritis is associated with left ventricular concentric remodeling: results of a population-based cross-sectional study. Arthritis Rheum 2013;65:1713-8.

26. Midtbø H, Gerdts E, Kvien TK, Olsen IC, Hirth A, Davidsen ES, et al. Disease activity and left ventricular structure in patients with rheumatoid arthritis. Rheumatology 2015;54:511-9.

27. Krishnan E. Gout and the risk for incident heart failure and systolic dysfunction. BMJ Open 2012;2:e000282.

28. Gerdts E, de Simone G, Lund BP, Okin PM, Wachtell K, Boman K, et al. Impact of overweight and obesity on cardiac benefit of antihypertensive treatment. Nutr Metab Cardiovasc Dis 2013;23:122-9.

29. de Simone G, Mancusi C, Izzo R, Losi MA, Aldo Ferrara L. Obesity and hypertensive heart disease: focus on body composition and sex differences. Diabetol Metab Syndr 2016;8:79.

30. Han C, Robinson DW, Hackett MV, Paramore LC, Fraeman KH, Bala MV. Cardiovascular disease and risk factors in patients with rheumatoid arthritis, psoriatic arthritis, and ankylosing spondylitis. J Rheumatol 2006;33:2167-72.

31. Haroon NN, Paterson JM, Li P, Inman RD, Haroon N. Patients with ankylosing spondylitis have increased cardiovascular and cerebrovascular mortality: a population-based study. Ann Intern Med 2015;163:409-16.

32. Cramariuc D, Gerdts E. Epidemiology of left ventricular hypertrophy in hypertension: implications for the clinic. Expert Rev Cardiovasc Ther 2016;14:915-26.

33. Klingberg E, Sveälv BG, Täng MS, Bech-Hanssen O, Forsblad-d'Elia H, Bergfeldt L. Aortic regurgitation is common in ankylosing spondylitis: time for routine echocardiography evaluation? Am J Med 2015;128:1244-50.
34. Kontos J, Papademetriou V, Wachtell K, Palmieri V, Liu JE, Gerdts $\mathrm{E}$, et al. Impact of valvular regurgitation on left ventricular geometry and function in hypertensive patients with left ventricular hypertrophy: the LIFE study. J Hum Hypertens 2004;18:431-6.

35. Singh JP, Evans JC, Levy D, Larson MG, Freed LA, Fuller DL, et al. Prevalence and clinical determinants of mitral, tricuspid, and aortic regurgitation (the Framingham Heart Study). Am J Cardiol 1999;83:897-902.

36. Devereux RB, Palmieri V, Sharpe N, De Quattro V, Bella JN, de Simone G, et al. Effects of once-daily angiotensin-converting enzyme inhibition and calcium channel blockade-based antihypertensive treatment regimens on left ventricular hypertrophy and diastolic filling in hypertension: the prospective randomized enalapril study evaluating regression of ventricular enlargement (preserve) trial. Circulation 2001;104:1248-54.

37. Lønnebakken MT, Izzo R, Mancusi C, Gerdts E, Losi MA, Canciello $\mathrm{G}$, et al. Left ventricular hypertrophy regression during antihypertensive treatment in an outpatient clinic (the Campania Salute Network). J Am Heart Assoc 2017;6:e004152.

38. de Simone G, Devereux RB, Izzo R, Girfoglio D, Lee ET, Howard $\mathrm{BV}$, et al. Lack of reduction of left ventricular mass in treated hypertension: the strong heart study. J Am Heart Assoc 2013;2:e000144.

39. Frieler RA, Mortensen RM. Immune cell and other noncardiomyocyte regulation of cardiac hypertrophy and remodeling. Circulation 2015;131:1019-30.

40. Arts EE, Fransen J, den Broeder AA, Popa CD, van Riel PL. The effect of disease duration and disease activity on the risk of cardiovascular disease in rheumatoid arthritis patients. Ann Rheum Dis 2015;74:998-1003.

41. Midtbø H, Semb AG, Matre K, Kvien TK, Gerdts E. Disease activity is associated with reduced left ventricular systolic myocardial function in patients with rheumatoid arthritis. Ann Rheum Dis 2017;76:371-6.

42. Arida A, Protogerou AD, Konstantonis G, Konsta M, Delicha EM, Kitas GD, et al. Subclinical atherosclerosis is not accelerated in patients with ankylosing spondylitis with low disease activity: new data and metaanalysis of published studies. J Rheumatol 2015;42:2098-105.

43. Biesbroek PS, Heslinga SC, Konings TC, van der Horst-Bruinsma IE, Hofman MBM, van de Ven PM, et al. Insights into cardiac involvement in ankylosing spondylitis from cardiovascular magnetic resonance. Heart 2017;103:745-52.

44. Lieb W, Xanthakis V, Sullivan LM, Aragam J, Pencina MJ, Larson $\mathrm{MG}$, et al. Longitudinal tracking of left ventricular mass over the adult life course: clinical correlates of short- and long-term change in the Framingham Offspring Study. Circulation 2009;119:3085-92.

45. Daïen CI, Fesler P, du Cailar G, Daïen V, Mura T, Dupuy AM, et al. Etanercept normalises left ventricular mass in patients with rheumatoid arthritis. Ann Rheum Dis 2013;72:881-7.

46. Kobayashi H, Kobayashi Y, Giles JT, Yoneyama K, Nakajima Y, Takei M. Tocilizumab treatment increases left ventricular ejection fraction and decreases left ventricular mass index in patients with rheumatoid arthritis without cardiac symptoms: assessed using 3.0 tesla cardiac magnetic resonance imaging. J Rheumatol 2014;41:1916-21

47. Sriramula S, Haque M, Majid DS, Francis J. Involvement of tumor necrosis factor-alpha in angiotensin II-mediated effects on salt appetite, hypertension, and cardiac hypertrophy. Hypertension 2008;51:1345-51.

48. Galderisi M, Henein MY, D’Hooge J, Sicari R, Badano LP, Zamorano JL, et al; European Association of Echocardiography. Recommendations of the European Association of Echocardiography: how to use echo-Doppler in clinical trials: different modalities for different purposes. Eur J Echocardiogr 2011;12:339-53. 